\title{
Industry engagement in a manufacturing simulation course
}

\section{Dr. Ali Alavizadeh, Indiana University Purdue University, Fort Wayne}

Dr. Ali Alavizadeh is an Assistant Professor in the MCET Department at Indiana University-Purdue University (Fort Wayne, Indiana). He has taught at the George Washington University (Washington, DC), and Morehead State University (Morehead, KY) in the fields of Engineering Management and Systems Engineering and in Industrial and Engineering Technology, respectively. His industrial experiences include enterprise architecture, systems analysis, and software engineering for private, governmental, and nongovernmental organizations. His research interests include system-of-systems modeling and simulation, enterprise architecture, and nonlinear dynamical systems. 


\section{Industry Engagement in a Manufacturing Simulation Course}

\section{Abstract}

This article presents the results of student involvement in two projects for a local manufacturing company in a manufacturing modeling and simulation course. The results presented served as a basis to enhance students learning experience, as well as to improve the ways by which such group projects can help local companies in their manufacturing endeavors.

The usage of modeling and simulation becomes pivotal as production systems and product/service development become increasingly complex. Engineering technology students need to be familiar with the simulation techniques in their field of study and more importantly, be able to conduct a simulation experiment and to derive applicable solutions. The latter can be achieved by having students work on a group project, which also addresses ABET's accreditation criteria on promoting students teamwork and communication skills.

The feedback provided by the students and the company at the end of the semester were encouraging and promising. Students mentioned that by doing real world projects they were able to see the challenges facing engineers in conducting simulation studies.

\section{Introduction}

Modeling and simulation play a crucial role in almost all disciplines in science and technology. In essence, modeling is the practice of developing a simplified representation of a system ${ }^{1}$. Simulation, on the other hand, is an imitation of the operation of the system over a period of time $^{2}$. Although until the 80's simulation was not popular due to the cost and long processing time of computing resources, today, simulation is considered an attractive and cost-effective method to perform systems analysis ${ }^{1}$.

Simulation may or may not be an appropriate tool, depending on the situation. For example, simulation is a useful tool to verify analytical solution, study and experimentation of a system or of a subsystem, or observing the impact of environmental and informational change on a model's behavior. However, it should not be used if a problem can be solved analytically, if it is less expensive to do experiments, or if the resources and time are not available to conduct a simulation study ${ }^{2,3}$.

Typically, a simulation study involves the following steps ${ }^{1,2}$ :

1- Problem description: a specific, clear statement of the problem, its objectives and scope, is formulated. Included in this step are identifying input parameters and performance measures, and as such.

2- Data collection: it is necessary to collect all the data required to build and simulate the model. For example, in a study to identify the bottleneck in a manufacturing assembly line, such data as cycle time, interarriaval time, machines' downtime are needed, to name a few. 
3- The model is built and implemented using a software package. Depending on the problem and its complexity, the appropriate software is chosen. Banks et all ${ }^{2}$ list and briefly describe some commercial software used in modeling and simulation.

4- Verification and Validation: the purpose of verification is to insure that the model is built right, while the purpose of validation is to insure that the right model is built ${ }^{4}$.

5- Conducting simulation experiments: after verifying and validating the mode, a set of simulation experiments (i.e., runs) is designed to run the simulation.

6- Output analysis: The performance measures are analyzed for each scenario to identify the optimum solution for the problem. Statistical analysis would be a tool used in the analysis.

7- Final recommendation: in this step, based on the results of output analysis, a set of recommendations is developed which is typically in the form of a written report.

The goal of offering a course on modeling and simulation in the program is to familiarize students with how to build and simulate models and how to implement the results. The course focuses on both theoretical and applied concepts with more emphasis on the application, which was achieved through student group projects. Although the emphasis was on the applicability of the group projects in the course, there is no guarantee that students can find such projects by their own and therefore, they may be forced to work on topics with little to no real world application. Consequently, students may not be able to see how the theory covered in the lectures can be implemented to solve industrial problems (e.g., using exponential distribution to model new jobs interarrival time, challenges in formulating the problem, data gathering, to name a few). Defining such projects with local industries would also promote the university's strategic plan for faculty/student and community/industry engagement.

Therefore, with the help of the University's Office of Research, Engagement, and Sponsored Programs, two real world projects were brought to the classroom to achieve the following two goals:

1- To provide students with an opportunity to apply the lessons learned in the real world.

2- To help local industries with their manufacturing challenges by promoting community engagement and mutual collaboration.

In this article, the author shares the experience of engaging a local manufacturing company in bringing two projects to the classroom, how the students and the company benefited from these projects, and the company's engagement in evaluating students projects from feasibility and implementation standpoints, through which students learned how their performance would be assessed and received.

\section{The structure of the courses}

A course on modeling and simulation is offered as an elective course in the Bachelor of Science Degree in Industrial Engineering Technology and Mechanical Engineering Technology in the university. In addition, an elective, graduate-level course on simulation modeling is offered to graduate students who pursue a Master of Science degree in Technology. The courses are offered every other semester. Due to relatively small class sizes in the Industrial Engineering 
Technology (IET), as well as in Master of Science in Technology programs, these courses are currently offered cross-listed (i.e., the class includes both graduate and undergraduate students). Typically, the first three weeks of the semesters are dedicated to review the theoretical foundation of modeling and simulation such as elements of discrete-event modeling and simulation, and probability and statistics, although other theoretical topics, such as random number generators and test of hypotheses are discussed later. Throughout the rest of the semester, various case studies and examples are discussed in which students learn about building models and interpreting the results using a software package (Figure 1). The topics covered in the course are shown in Table 1.

\begin{tabular}{|c|c|}
\hline Topic & Duration (approximation) \\
\hline $\begin{array}{ll}\text { - } & \text { Discrete-Event Modeling and } \\
& \text { Simulation } \\
\text { - } & \text { Statistics and Probability }\end{array}$ & 3 weeks \\
\hline $\begin{array}{ll}- & \text { Random numbers } \\
- & \text { Introduction to ARENA }\end{array}$ & 2 weeks \\
\hline $\begin{array}{ll}- & \text { Model Testing (Verification and } \\
& \text { Validation) } \\
- & \text { Input Analysis } \\
- & \text { Model Goodness } \\
\end{array}$ & 6 weeks \\
\hline $\begin{array}{l}\text { - Case studies } \\
-\quad \text { Group project finalization }\end{array}$ & 3 weeks \\
\hline
\end{tabular}

Table 1. The topics discussed in the course.

The objectives of the course were as follows:

1- Learn the purpose and usage of modeling and simulation, model building, model verification, and result interpretation.

2- Understand and apply statistics and probability as is used in simulation analysis.

3- Use a simulation tool to model and simulate manufacturing systems.

4- Be able to complete a manufacturing system simulation project from beginning to end.

\section{Assignments and reflection papers}

Both undergraduate and graduate students worked on identical problems, although graduate students worked on a few more problems. The assignments covering the basis of modeling and simulation (i.e., statistical distribution, random numbers, etc.) were submitted in written format, while the later assignments on building and running models were submitted electronically via Blackboard. For the latter, students submitted the reports generated by the simulation software and highlighted the answers and, if needed, provided their own thoughts and interpretation of the results. 


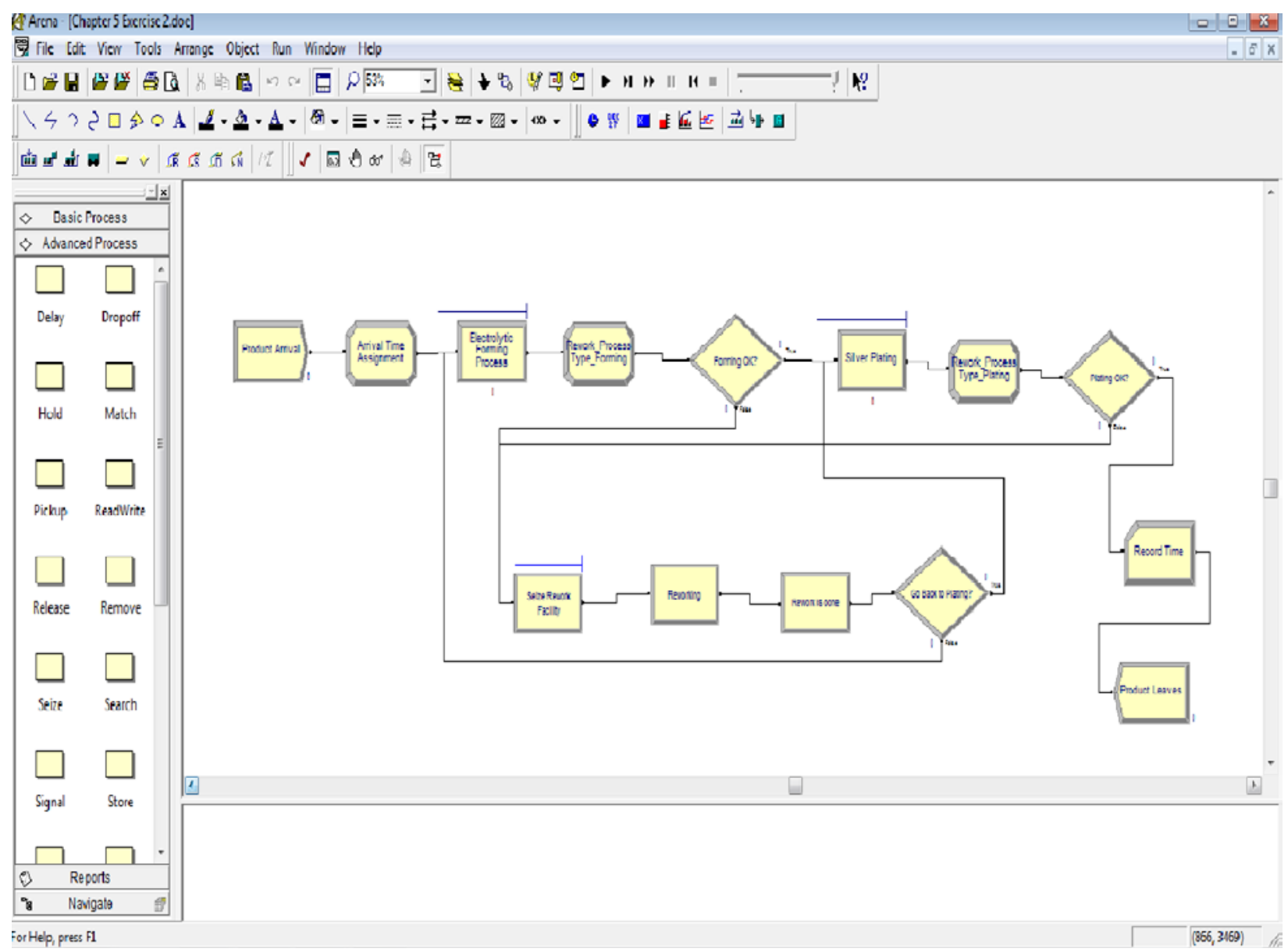

Figure 1. A snapshot of ARENA

Graduate students had to submit reflection papers, in addition to the assignments. Each student chooses a topic of his/her interest related to modeling and simulation in manufacturing, production, supply chain management, logistics, service industries, and the like. In particular, a topic pertaining to the student's group project was encouraged. Each graduate student would find articles that were recently published in scholarly journals (2005 onward). The reflection paper could take the form of a commentary in which the student identifies a theme in the articles and/or pose a question that was raised for him/her during the readings and then try to answer it. IEEE citation guidelines for document preparation were mandatory for both the reflection paper and the final group reports.

\section{Exams}

As far as exams for cross-listed courses, the instructor traditionally gives an in-class midterm and a final exam to undergraduate students and only a take-home midterm exam to graduate students. However, introducing real world projects posed a challenge, which will be discussed later, as far as the work load for the groups. Consequently, only the midterm exam was given and the final exam was cancelled. 


\section{Student groups}

As mentioned earlier, there were two groups whose members were a mix of undergraduate and graduate students and were assigned randomly. Graduate students had the role of project leads. They provided guidelines and more in depth analysis on the project requirements and also, insured that everything would be documented and communicated with the company's managers (e.g., those who presented the projects to the class). Undergraduate students were mainly involved with solution development, building and simulating models, and final documentation and presentation. It should be mentioned that all of these activities were performed collaboratively among team members. The difference was mainly on the responsibility, project management, and leadership that would differentiate graduate from undergraduate students.

\section{The group projects}

With the help of the university's Office of Research, Engagement, and Sponsored Programs, a local manufacturing company was contacted to inquire about potential projects that could be defined for the class. The company identified was one of the suppliers of high stress suspension U-bolts for trucks and buses in the United States. During a facility tour provided to the instructor and the director of the Office of Research, Engagement, and Sponsored Programs, two projects were identified and agreed upon for the class: bending operation and Zinc Phosphate operation.

In the bending operation, there were three bending machines, each of which would complete 800 parts per day with one operator assigned to each machine. Each operator was also, in charge of quality check and material handling. They were interested to add one more bending machine and to add two more workers who would be in charge of only the material handling and quality check for all four machines (one operator per two machines). The management was wondering what impact this change would have on the operation's throughput and cycle time.

The Zinc Phosphate operation consisted of one machine and one operator. After parts leaving this station, they would go to the final audit prior to shipment. However, due to the shipment delay, the management was curious to know if they could expedite the shipment by bringing the final audit check closer to the Zinc Phosphate. For both of these projects, some estimated data, such as cycle time, was available but not so accurate, as the managers mentioned. In addition, the managers stated that they had been planning on tackling these problems for months but due to the lack of time and resources, it was delayed. They were hoping that students' findings would help them improve these operations.

The process and production managers presented the projects in the class to the students and each group selected one project to work on. Tentative deadlines, methods of communication, and format of the reports that groups should submit were also, discussed.

The projects were completed in three phases, as shown in Figure 2. 

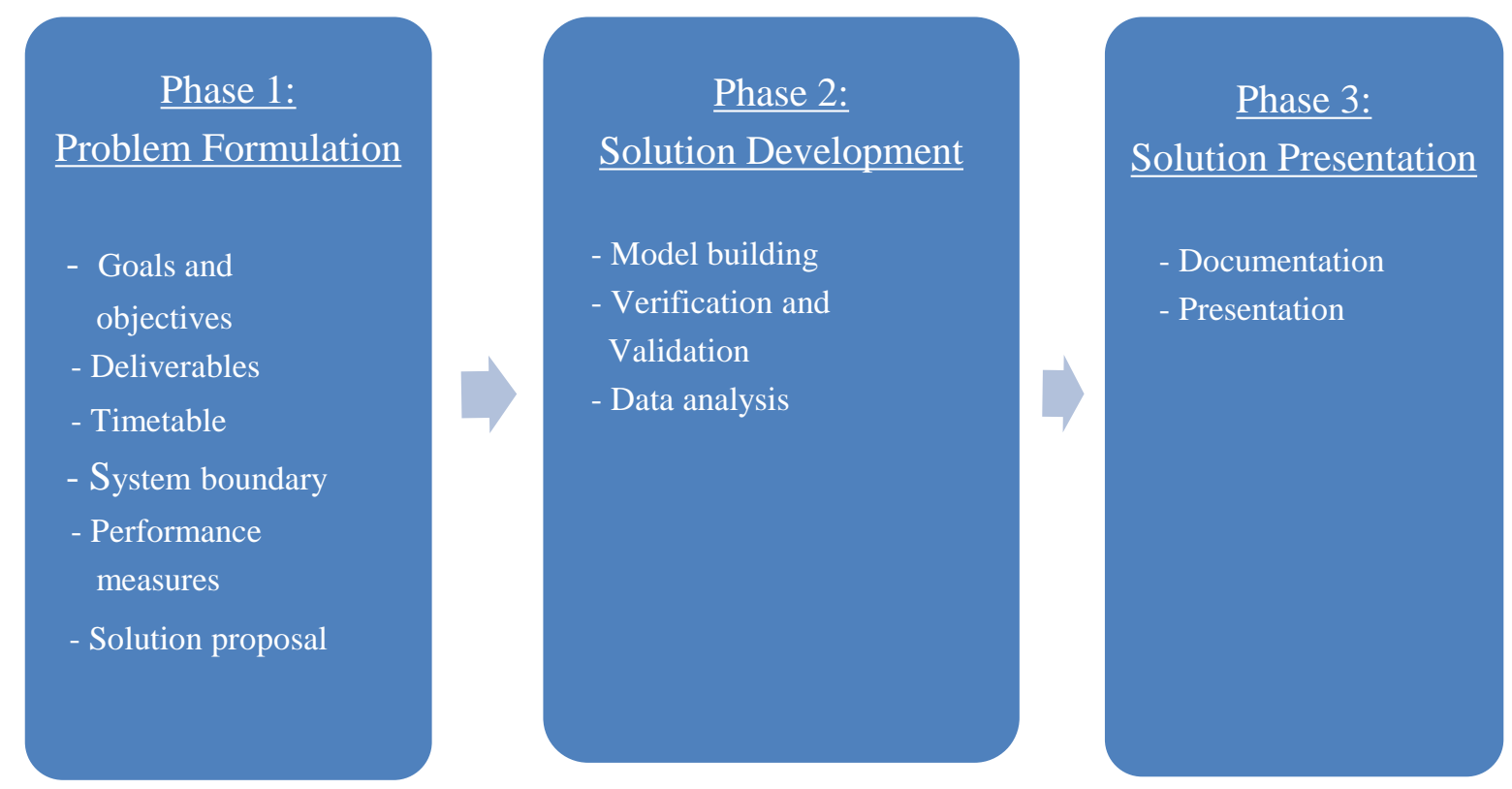

Figure 2: group project phases.

Phase 1: Problem formulation: The company's managers presented the projects to the students and during the discussions, the goals and scope of each project was discussed and agreed upon. Within the next three weeks, each group developed a solution proposal as to how to solve the problem, what should be modeled, what information needed, as well as a Gantt chart that tentatively showed the project milestones. This was done by graduate students and submitted to the company to seek their thoughts and advise. Once approved, the groups started working on the second phase.

Phase 2: Solution development: In this phase groups made several visits to the company to observe the system and to inquire about the available data that would be used in simulation. During this phase, it was determined that some data were missing and therefore, students needed to do a time measurement to be used as a baseline for their simulation. Another activity that was done simultaneously was to build and verify the model. Model validation was postponed until all the data was gathered and incorporated into the model.

Phase 3: Solution presentation: Each group prepared a written document, detailing the model, simulation results, and recommendations, as well as a power point file that summarized the study. Each group presented the findings, followed by a question and answer section. All the audiences, including the students and the company's representatives were given project evaluation forms and, upon finishing the presentations, they submitted the forms to the instructor. Furthermore, each student was given a peer evaluation form to evaluate his/her teammates. Appendices 1 and 2 include a sample of these evaluation forms. The group project grade for each student was calculated based on feedbacks received from the company's managers, students' peer and class evaluations, and the instructor assessment of the project. 


\section{Projects Results}

Each student group analyzed the assigned problem, studied the as-is system, and modeled and simulated it. Group 1 was working on the bending operation as described in the group projects above, and concluded that by adding one more machine and two operators, the bending operation could increase its throughput from 100 parts per hour per machine to 300. For this, they should re-arrange the machines location and add an extra part holding rail to facilitate parts movement.

Group 2 completed the Zinc Phosphate project and based on the analysis, it turned out that bringing the final audit check alone to the Zinc Phosphate operation would not address the bottleneck in the shipment department because $85 \%$ of the products go to the Zinc Phosphate operation and $15 \%$ go directly to the final audit. Rather, a change in the queue discipline, i.e., make it a FIFO, would decrease the delay in the final audit station. In addition, an extra operator can be added to the station would expedite moving parts from the station to the final audit. S

\section{Discussion}

Overall, the results of bringing real world projects were encouraging and positive, particularly, for students with less industrial experience. It is possible that one uses case studies that are discussed in some textbooks or research projects. However, the majority of such case studies are already solved, "bugged out" projects, for which all the necessary information was already given. Therefore, students may not be challenged to figure out what information they might need and what obstacle they may face when conducting real world projects.

There are potential challenges in using such projects as discussed below:

- The impact of projects' unknowns on the course requirements and assessment should be considered. For example, the instructor had planned on giving a total number of 10 assignments during the semester with a final exam that was only for undergraduate students. However, since both of the groups needed extra time to do a work measurement study and collect input data for their model, the instructor had to reduce the number of assignments and cancelled the final exam to accommodate the students. Since it was the first time that such projects were brought to the classroom, both the instructor and students were eager to do a satisfactorily job that would encourage the company for future collaboration and would promote community engagement through the company's referral in the region.

- The projects requirements and scope may change over the period of time. It is crucial that students follow the objectives that were agreed upon in Phase 1 (Figure 2) and if the company makes any modification in those, the groups should be aware of it and be able to assess the impact of such modifications on the deliverables and project duration.

- Time management can be an issue. Students needed to visit the company several times, which were out of the class time. One problem can be finding a common time that would work for everyone, especially for the company. Some key personnel may work during certain shifts (third or even weekends), which implies that the students would need to 
plan for more plant visits and/or find ways to obtain the information they need. Although this is a good experience for students to learn about planning, it may delay the progress of the project.

- Validation was discussed in the class but as far as the projects it was not performed completely. One reason was the lack of time. However, a more important reason was the lack of reliable data that was necessary to validate the model. As mentioned earlier, students had to do time studies which could be a separate project suitable for a course on work measurement. This constraint was discussed with the company's managers during the presentations.

- The type of software license that was used in the course added another challenge. Due to the limited number of entities that could be modeled with the available version, the groups had to simplify their models and to use estimations (e.g., each entity that represents a product was considered to be 100 products), yet, the model was realistic. Due to financial issues, it was impossible to purchase a site license to avoid the challenge. However, for future, the instructor is planning to use a different software package within the financial constraint.

\section{Conclusion}

Based on the feedback received from the students, as well as the company, the result of implementing real world projects in the course was satisfactory. Students expressed their enthusiasm to work on the projects and their learning outcomes. For example, some students mentioned that that problems in textbooks are clean, already-solved problems that would not let them learn what real challenges might be (e.g., one cannot assume that all the information are available to solve the problem or the pressure of deadline).

As far as the company, it was the first time that they had been offered such a collaborative opportunity. Both the managers, who attended the presentations, stated that they were pleased with the results of the projects. This was in particular, useful since they had observed the problems in both the bending and Zinc Phosphate operations but had not been able to dedicate time and resources to study them. In their evaluation surveys, one of the managers mentioned that the written report provided by both groups were helpful because the simulation results and the recommendations were all documented.

Future collaboration opportunities were discussed with the instructor, in terms of class projects for other courses such as optimization. Since there were four graduate students in the course and the project findings suggested further investigation to fully address the issues, some students showed their enthusiasm to work on the problems as their Masters' directed projects. During the semester, the company forwarded summer job opportunities for students to the instructor to be shared with the students.

The instructor believes that this experience helped him continue to bring such projects to his classes. The project evaluation survey distributed among all the students indicated that they were 
interested in seeing how theoretical aspects would be implemented in real world situation and what obstacles one may face in solving those problems. For example, one student stated that: "Real world projects should be done like this in every class. The things learned are far superior to any book material and assignments. The more classes begin to do projects like this, the more students will be prepared for the real world.” Furthermore, the majority of students found the assignments and lab activities relatively helpful and relevant (rating them on average 3.3 out of 5), which would be an area that needs improvement.

\section{Reference}

[1] T. Altiok and B. Melamed, Simulation Modeling and Analysis with ARENA. Burlington, MA: Academic Press, 2007.

[2] J. Bank, J. S. Carso II, B. L. Nelson and D. M. Nicol. Discrete-Event System Simulation. $5^{\text {th }}$ ed. Upper Saddle River, NJ: Prentice Hall, 2010.

[3] J. Banks and R. R. Gibson. "Don't Simulate When: 10 Rules for Determining when Simulation Is Not Appropriate,” IIE Solutions, September 1997.

[4] D. K. Pace, "Modeling and Simulation Verification and Validation Challenges", The Johns Hopkins APL Technical Digest, vol. 25, no. 2, 2004, pp. 163-172. [Online] Available:

http://www.jhuapl.edu/techdigest/TD/td2502/Pace.pdf [Access: [12 Dec. 2012]. 
Appendix 1: Project evaluation form

Instruction: On scale 1 to 5, 5 being excellent and 1 being poor, please evaluate the group’s presentation.

\begin{tabular}{|c|c|c|}
\hline Criteria & & Evaluation \\
\hline \multicolumn{3}{|l|}{ Presentation } \\
\hline Introduction & 5 & 2 \\
\hline Statement of the problem, scope, limitation, etc. & 5 & 43 \\
\hline Methodology & 5 & 43 \\
\hline Data analysis, discussion, recommendations & 5 & 43 \\
\hline $\begin{array}{l}\text { Presentation skill (i.e., clarity of language, body language, pace), } \\
\text { punctuations, grammar }\end{array}$ & 5 & 43 \\
\hline Adequate audio/visual aids (i.e., graphs, drawings, tables, videos, etc.) & 5 & 43 \\
\hline Time management & 5 & 43 \\
\hline Overall presentation & 5 & 43 \\
\hline \multicolumn{3}{|l|}{ Solution proposed } \\
\hline Addressing questions & 5 & $\begin{array}{llll}4 & 3 & 2 & 1\end{array}$ \\
\hline Quality of the solution and analysis (i.e., depth, comprehensiveness) & 5 & 43 \\
\hline Feasibility of implementing the solution & 5 & 43 \\
\hline \multicolumn{3}{|l|}{ Collaboration/communication with the customer } \\
\hline Understanding of the project and customer requirements & 5 & $\begin{array}{llll}4 & 3 & 2 & 1\end{array}$ \\
\hline Initial study (i.e., site visit, data gathering, etc.) & 5 & $\begin{array}{llll}4 & 3 & 2 & 1\end{array}$ \\
\hline Communication/follow up with the customer & 5 & $\begin{array}{llll}4 & 3 & 2 & 1\end{array}$ \\
\hline
\end{tabular}


Appendix 2: Peer evaluation form

Instruction: On scale 1 to 5,5 being excellent and 1 being poor, please evaluate your colleagues as listed below:

\begin{tabular}{|l|l|l|l|c|c|}
\hline Name & Collaboration & Communication & $\begin{array}{c}\text { Timely } \\
\text { delivery }\end{array}$ & $\begin{array}{c}\text { Work } \\
\text { Attitude }\end{array}$ & $\begin{array}{c}\text { Overall } \\
\text { evaluation }\end{array}$ \\
\hline & & & & & \\
\hline & & & & & \\
\hline & & & & & \\
\hline
\end{tabular}

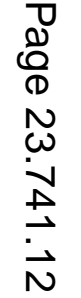

